\title{
Luteinizing hormone-releasing hormone receptor-mediated delivery of mitoxantrone using LHRH analogs modified with PEGylated liposomes
}

This article was published in the following Dove Press journal:

International Journal of Nanomedicine

17 September 2010

Number of times this article has been viewed

Yingna He

Linhua Zhang

Cunxian Song

Key Laboratory of Biomedical Material of Tianjin, Institute of Biomedical Engineering, Peking Union Medical College and Chinese Academy of Medical Sciences, Tianjin, China
Correspondence: Cunxian Song Institute of Biomedical Engineering, Peking Union Medical College and Chinese Academy of Medical Sciences, Tianjin 300192, China

Tel +86022 87892052

Email scxian@tom.com
Abstract: A sterically stabilized, mitoxantrone-loaded liposome, tailored to target luteinizing hormone-releasing hormone (LHRH) receptor overexpressing cells, was developed to promote the efficiency of intracellular delivery of mitoxantrone through receptor-mediated endocytosis. Liposomes were prepared by lipid film hydration and an ultrasound dispersion process. Thiolated gonadorelin with affinity for the LHRH receptor was chemically coupled to N-[(3-maleimide-1-oxopropyl) aminopropyl polyethylene glycol-carbamyl] distearoyl-1phosphatidyl-ethanolamine via a thioether bond and subsequently inserted into polyethylene glycol-grafted liposomes. The liposome was characterized in terms of its size, ligand density, drug loading, and leakage properties. The targeting nature and antitumor effects of the liposomes were evaluated in vitro using cultured MCF-7 breast cancer cells. A protein assay of ligand coupling to the liposomal surface indicated that more than $60 \%$ of the LHRH peptides were inserted into the liposome bilayer. Up to $1.0 \mathrm{mg} / \mathrm{mL}$ of stable liposomal mitoxantrone loading was achieved, with approximately $98 \%$ of this being entrapped within the liposomes. In vitro cell culture studies revealed that the gonadorelin-modified liposomes bound to their target cells had significantly higher affinity and better antitumor efficiency than generic drug-loaded liposomes. These events were presumed to occur through specific interactions of the LHRH with its cognate receptors on the cell surface. It was concluded that the targeting properties of the delivery system would potentially improve the therapeutic benefits of mitoxantrone, as compared with nontargeted liposomes.

Keywords: mitoxantrone, liposome, luteinizing hormone-releasing hormone receptor, tumor targeting

\section{Introduction}

Chemotherapy is a common procedure for the treatment of advanced or metastatic cancer. ${ }^{1}$ However, the application of free anticancer drugs has several drawbacks, including lack of selectivity, toxicity to normal cells, rapid elimination from the circulation, and instigation of acquired or intrinsic multidrug resistance of cancer cells. ${ }^{2}$ Targeted delivery of anticancer drugs to tumors may assist in resolving these issues. Currently, an attractive solution is based on the use of nanocarriers. Encapsulation of anticancer drugs within such carriers could minimize drug degradation, prevent undesirable side effects, and increase the fraction of the drug accumulated in the diseased tissue.

Liposomes represent one of the most efficient and well characterized drug delivery strategies for small molecules. ${ }^{3}$ These particles are biodegradable, biologically inert, have no antigenic or pyrogenic reactions, and possess limited intrinsic toxicity. 
Moreover, liposomes are better suited for drug targeting because of the ease of modifying their surface structure when compared with other drug carriers. Rationally designed liposomes, such as polyethylene glycol (PEG)-grafted liposomes (PEGylated liposomes), have the ability to accumulate passively in tumor tissues via "leaky" vasculature through the enhanced permeability and retention effect. ${ }^{4}$ This passive accumulation can be further enhanced by actively targeting PEGylated liposomes to these tumor areas. Targeting of such liposomes could potentially reduce the extent of nonspecific toxicity associated with many drugs.

Targeting can be achieved by attaching a ligand for specific receptors that are expressed preferentially on tumor cells. Use of ligand-targeted liposomes has been demonstrated to result in increased internalization and more effective nuclear delivery of anticancer drugs, thus overcoming the problem of multiple drug resistance. ${ }^{5}$ The luteinizing hormone-releasing hormone (LHRH) receptor is characteristically overexpressed in many tumors, such as breast, ovarian, endometrial, prostate, hepatic, colorectal, and pancreatic cancers, renal cell carcinomas, nervous system tumors, oral and laryngeal carcinomas, and melanomas, but is barely expressed in healthy visceral organs. ${ }^{6-8}$ The elevated expression of LHRH receptors in various cancers makes it possible to use these receptors as target moieties to deliver cytotoxic agents. ${ }^{9}$ Analogs of LHRH have reportedly been used to deliver cytotoxic molecules to the tumor, and these cytotoxic analogs can be internalized by human ovarian and endometrial cancer cells ${ }^{10-12}$ and MCF-7 human breast cancer cells. ${ }^{13,14}$

Mitoxantrone, a synthetic anthraquinone drug, has high antitumor activity against acute nonlymphocytic leukemia, advanced breast cancer, and non-Hodgkin's lymphomas. The dose-limiting toxicity associated with mitoxantrone is myelosuppression combined with cardiotoxicity. ${ }^{15,16}$ Encapsulation of mitoxantrone into PEGylated liposomes not only increases the tumor concentration of the drug via the permeability and retention effect but also decreases its biodistribution and, consequently, the toxicity associated with therapy. ${ }^{17-20}$

Several attempts have been made to improve the anticancer efficiency of liposomal mitoxantrone further by modifying it with vector molecules specific to receptors typical for cancerous cells. Folate-targeted liposomes loaded with mitoxantrone demonstrated a substantial increase in cytotoxicity toward target cells in vitro. ${ }^{21}$ Similarly notable results were obtained with mitoxantrone-loaded liposomes composed of anti-epidermal growth factor receptor monoclonal antibody fragments. ${ }^{22}$ Most of the vector molecules being investigated now are proteins (first of all, monoclonal antibodies) specific to only certain types of tumors. Some small peptide LHRH analogs among these molecules possess an ability to recognize a broad variety of tumors, but not normal cells. Targeting these small peptides has certain advantages, including ease of preparation, lower antigenicity, and increased stability over the use of conventional protein macromolecules. LHRH analog-modified nanocarriers have been used for the selective delivery of diagnostic or therapeutic agents to LHRH receptors overexpressing cancer cells. Its improved efficacy over nontargeted nanoparticles was also clearly evident in previous studies. ${ }^{23-25}$

We have developed a simple and efficient way to attach gonadorelin to the liposomal membrane. Procedures for the attachment of LHRH analogs to the liposome surface using electrostatic absorption or conventional coupling techniques have been previously reported..$^{26,27}$ In these two approaches, the ligand was incorporated in the lipid bilayer during their formation which involves several steps and a considerable length of time, and leaves some reactive functional groups on the inner leaflet of the lipid bilayer. In our current work, an alternative design was used, whereby the ligand was first modified with an activated lipid derivative and then incorporated into liposomes by coincubating the micelles of peptide-PEG-DSPE with preformed liposomes. An advantage of this approach is that the preparation of liposomes and the modification of ligand are performed separately, allowing the selection of optimal conditions for each step. The resulting liposomes exhibited strong and selective binding ability to the LHRH receptor on overexpressing tumor cell lines, and subsequent internalization. Furthermore, when compared with generic drug-loaded liposomes, targeting led to a selective increase in cytotoxicity of the mitoxantroneloaded liposomes toward LHRH-receptor overexpressing tumor cell lines.

\section{Materials and methods Materials}

A peptide analog of LHRH, gonadorelin (a synthetic human luteinizing hormone-releasing hormone), was purchased from ProSpec-Tany TechnoGene Ltd (Rehovot, Israel). The sequence of gonadorelin was Pyr-His-Trp-Ser-TyrGly-Leu-Arg-Pro-Gly-NH2 (molecular weight 1182.3). Mitoxantrone hydrochloride was obtained from Chongqing Kailin Pharmaceutical Co., Ltd (Chongqing, China). Hydrogenated soybean phosphatidylcholine (HSPC) and [N-(carbonyl-methoxypolyethylene glycol 2000)-1, 2-distearoyl-sn-glycero-3-phosphoethanolamine sodium 
salt] (mPEG2000-DSPE) were purchased from Lipoid (Ludwigshafen, Germany). Cholesterol, 2-iminothiolane (Traut's Reagent), 3-(4,5-dimethylthiazol-2-yl) 2, 5-diphenyltetrazolium bromide (MTT), and Sephadex G10 were purchased from Sigma Chemical Co (St. Louis, MO). Maleimide-PEG2000-DSPE (Mal-PEG2000-DSPE) was purchased from Avanti Polar Lipids (Alabaster, AL). Phosphate-buffered saline ( $\mathrm{pH} \mathrm{7.4,} 290$ mosm) was purchased from Tianjin Haoyang Biologicals Technology Co., Ltd (Tianjin, China). The bicinchoninic acid kit was purchased from Shanghai Shenergy Bicolor Bioscience and Technology Co (Shanhai, China). Ammonium sulfate and all other chemicals used in this study were of analytical grade or of high-performance liquid chromatography grade.

\section{Cell line}

Human MCF-7 breast cancer cells (LHRH receptor overexpressing cancer cell line) and human ovarian cancer SK-OV-3 cells (LHRH receptor low-expressing cancer cell line) were purchased from the American Type Culture Collection (Manassas, VA). Cells were cultured in RPMI 1640 medium (Sigma) supplemented with $10 \%$ fetal bovine serum (Tianjin Haoyang Biologicals Technology Co., Ltd). Cells were grown at $37^{\circ} \mathrm{C}$ in a humidified atmosphere of $5 \%$ $\mathrm{CO}_{2}$ ( vol/vol) in air. All experiments were performed on cells during the exponential growth phase.

\section{Preparation of PEGylated liposomes}

Liposomes were prepared by lipid film hydration and ultrasonic dispersion. Briefly, the mixtures of HSPC, cholesterol, and mPEG2000-DSPE (molar ratio 90:10:0.4) were solubilized in chloroform and dried to a thin lipid film at $60^{\circ} \mathrm{C}$, followed by incubation overnight under vacuum to remove residual solvent. The dried lipid films were subsequently hydrated with $300 \mathrm{mM}$ ammonium sulfate at $60^{\circ} \mathrm{C}$ for one hour, and subjected to sonication (VCX130-PB; Sonics, Newtown, CT) for 10 minutes at $4^{\circ} \mathrm{C}$ (two minute pulses and two minutes of rest). This procedure formed small unilamellar vesicles. Small unilamellar vesicles were then centrifuged at $1000 \mathrm{~g}$ for 10 minutes to remove any titanium particles and larger aggregates. The particle size, polydispersity index, and zeta potential of the liposomes were determined by dynamic light scattering techniques (Zeta sizer Nano ZS; Malvern Instruments Ltd., UK) at $25^{\circ} \mathrm{C}$ and at a scattering angle of $90^{\circ}$. The obtained particle suspension was diluted appropriately in phosphate-buffered saline before measurement.

\section{Preparation of thiolated gonadorelin and coupling procedure}

Gonadorelin and Traut's reagent were both dissolved in HEPES buffer (25 mM HEPES, $140 \mathrm{mM} \mathrm{NaCl}, \mathrm{pH}$ 8.0) and mixed at a 1:4 molar ratio. This mixture was left to react for one hour, at room temperature, under dark conditions and under an inert $\mathrm{N}_{2}$ atmosphere. Unreacted Traut's reagent was removed by size exclusion chromatography using a Sephadex G10 column with degassed HEPES buffer ( $\mathrm{pH}$ 8.0). Separately, the dried lipid films of Mal-PEG2000-DSPE were prehydrated at a concentration of $4 \mathrm{mg} / \mathrm{mL}$ in HEPES buffer $\left(\mathrm{pH} \mathrm{8.0)}\right.$ at $60^{\circ} \mathrm{C}$ to form micelles. The thiolated-gonadorelin was then added to freshly prepared Mal-PEG2000-DSPE micelles at a 2:1 molar ratio. The resulting suspension was left to react overnight in the dark at room temperature with magnetic stirring under an inert $\mathrm{N}_{2}$ atmosphere. Free maleimide groups were quenched with an excess of histidine for 30 minutes at room temperature. Gonadorelin-coupled PEG-DSPE micelles were then concentrated in a Centriprep ${ }^{\circledR}$ Centrifugal filter, using a size cutoff of $3000 \mathrm{Da}$ (Millipore, Billerica, MA). The amounts of conjugated and free gonadorelin were indirectly measured with a bicinchonic acid protein assay using pure bovine serum albumin as standard. ${ }^{30}$ The coupling efficiency of gonadorelin to Mal-PEG-DSPE was calculated as $\mu$ g gonadorelin/ $\mu$ mol lipid.

\section{Preparation of gonadorelin-modified liposomes}

Gonadorelin-PEG-DSPE was then transferred into preformed PEGylated liposomes based on the procedure described previously. ${ }^{25,26}$ Briefly, the gonadorelin-PEG-DSPE solution was added to the preformed PEGylated liposome solution at 1:1000 gonadorelin-PEG-DSPE:phospholipid molar ratios and incubated at $60^{\circ} \mathrm{C}$ for one hour. The control PEGylated liposomes were prepared similarly by substituting gonadorelin-PEG-DSPE with mPEG2000-DSPE.

\section{Transmembrane ammonium sulfate gradient loading of mitoxantrone}

Mitoxantrone was encapsulated into the gonadorelin-modified or control PEGylated liposome formulations using transmembrane ammonium sulfate gradient-driven loading procedures. The procedure consisted of initially exchanging the buffer by dialysis for four hours against sucrose (300 mM)-histidine $(10 \mathrm{mM})$ buffer ( $\mathrm{pH} 7.5)$, using dialysis tubing with a 10-12 kDa molecular weight cutoff (Pierce Chemical Co., Rockford, IL). Liposomes were incubated at $60^{\circ} \mathrm{C}$ for 
10 minutes before addition of mitoxantrone, to achieve a final lipid to drug weight ratio of 10:1. The resulting mixture was incubated at $60^{\circ} \mathrm{C}$ for an additional 30 minutes, followed by dialysis against phosphate-buffered saline to remove the free mitoxantrone for determination of entrapment efficiency. The concentration of mitoxantrone was determined by measuring absorbance at $655 \mathrm{~nm}$ in a Varioskan Flash spectral scanning multimode reader (Thermo Scientific, Waltham, MA) after lysis of liposomes with 3\% Triton-X 100 .

\section{In vitro drug release}

Drug release experiments were performed in two different release buffers, (release buffer 1: phosphate-buffered saline at pH 7.4 and release buffer 2: 90\% isotonic glucose solution buffered with $10 \mathrm{mM}$ histidine to $\mathrm{pH} 7.5$ and $10 \%$ human plasma). The liposomes were first diluted using the release media, to a HSPC concentration of $20 \mathrm{mM}$, and then $2 \mathrm{~mL}$ of diluted liposomes were put into dialysis tubing with a molecular weight cutoff of 10-12 kDa and dialyzed against $100 \mathrm{~mL}$ release buffers at $37^{\circ} \mathrm{C}$. Each buffer contained $100 \mathrm{IU} / \mathrm{mL}$ penicillin and $100 \mu \mathrm{g} / \mathrm{mL}$ streptomycin.

At predetermined time intervals, samples were withdrawn from the release medium and assayed for mitoxantrone by high-performance liquid chromatography. Before analysis, samples containing plasma were extracted by protein precipitation, ${ }^{31}$ and samples without plasma were analyzed directly. Mitoxantrone was separated on a Zorbax SB C18 column $(150 \mathrm{~mm} \times 4.6 \mathrm{~mm}, 5 \mu \mathrm{m}$, Agilent Technologies, Inc. Santa Clara, CA) at $35^{\circ} \mathrm{C}$, and quantified by ultraviolet absorbance at $655 \mathrm{~nm}$. The mobile phase consisted of acetonitrile and solutions containing $30 \mathrm{mM}$ of sodium 1-heptanesulfonate and $9.0 \mathrm{ml} / \mathrm{L}$ of glacial acetic acid (37:63, $\mathrm{v} / \mathrm{v}$ ) at a flow rate of $1 \mathrm{~mL} / \mathrm{min}$.

\section{In vitro intracellular uptake of liposomal mitoxantrone}

LHRH receptor overexpressing MCF-7 cells or LHRH receptor low-expressing $\mathrm{SK}-\mathrm{OV}-3$ cells were seeded at densities of $2 \times 10^{5} \mathrm{~cm}^{-2}$ in $35 \mathrm{~mm}$ diameter culture dishes and cultured in RPMI 1640 medium. After 24 hours of incubation, $50 \%$ confluency was reached and the medium was changed with $1 \mathrm{~mL}$ of fresh culture medium containing either gonadorelin-modified mitoxantrone-loaded liposomes (LHRH-MTX-SL) or nontarget mitoxantroneloaded liposomes (MTX-SL) at a dose of $0.2 \mathrm{mg}$ total lipids ( $10 \mu \mathrm{g} / \mathrm{mL}$ as mitoxantrone) per dish. The cells were treated identically, except for the omission of reacting with mitoxantrone formulations was used as a negative control.
After four hours of incubation at $37^{\circ} \mathrm{C}$, the cells were washed three times with cold phosphate-buffered saline ( $\mathrm{pH} 7.4)$ to remove unbound liposomes. The internalized liposomes were visualized using a confocal laser scanning microscope (Zeiss LSM 510, Germany), with excitation and emission wavelengths for mitoxantrone of $514 \mathrm{~nm}$ and $685 \mathrm{~nm}$, respectively.

\section{In vitro antitumor effect}

A comparison of the cytotoxicity of free drug and various liposomal formulations was performed on human MCF-7 cells by means of an in vitro proliferation assay using MTT. Briefly, $2 \times 10^{5}$ cells were seeded in 96-well plates and incubated overnight. Culture media with various concentrations of free mitoxantrone or its liposomal formulations were then added in sextuplet, and incubation continued for an additional 24-120 hours. At designated time points, the medium was discarded and fresh medium containing MTT was added to each well. After four hours, the medium was removed, replaced with $100 \mu \mathrm{L}$ methyl sulfoxide, and mixed on a vortex mixer for 10 minutes. Absorbance was recorded at $570 \mathrm{~nm}$ using the Varioskan Flash spectral scanning multimode reader. Cell viability was calculated as follows:

$$
\text { viability }(\%)=\mathrm{A}_{\text {treated }} / \mathrm{A}_{\text {control }} \times 100 \%
$$

$\mathrm{IC}_{50}$ was defined as the concentration of drug that reduced the optical density measured at $570 \mathrm{~nm}$ by $50 \%$ of the control value.

\section{Statistical analyses}

Statistical comparisons were carried out using one-way analysis of variance with SPSS 10.0 software (SPSS Inc., Chicago, IL). $P$ values less than 0.05 were considered significant.

\section{Results \\ Preparation and characterization of liposomal formulations}

Gonadorelin-modified PEGylated liposomes were produced by transferring the conjugate of DSPE-PEG and gonadorelin from their loose micelles onto the liposome surface. Liposomes consisted of small unilamellar vesicles containing HSPC, cholesterol, mPEG2000-DSPE, and Mal-PEG-DSPE for ligand conjugation. As controls, nontargeted PEGylated liposomes were prepared identically, except for the substitution of mPEG2000-DSPE for gonadorelin-PEG-DSPE. Liposomes were then loaded with mitoxantrone using the 
transmembrane ammonium sulfate gradient loading method (Figure 1). Up to $1.0 \mathrm{mg} / \mathrm{mL}$ of stable liposomal mitoxantrone loading was achieved, with approximately $98 \%$ of this being entrapped within the liposomes. The physical properties of the liposomes before and after coupling of gonadorelin are presented in Table 1. The size of the liposomes was in the range of 120-150 $\mathrm{nm}$. The size of the gonadorelin-modified liposomes was found to be $15-20 \mathrm{~nm}$ larger than the original liposome. The zeta potential was slightly lower after the ligand conjugation event due to the presence of peptides attached to the liposomal membrane via a longer PEG-linker. Regardless, the encapsulation of mitoxantrone did not significantly affect the particle size of the liposome. The amount of gonadorelin in the liposome (assessed by bicinchoninic acid assay) in comparison with the amount of total phospholipids ${ }^{30}$ are also presented in Table 1.

\section{In vitro release of liposomal mitoxantrone}

The in vitro release experiments were performed for quantitative comparison of the drug release characteristics of mitoxantrone from different mitoxantrone-loaded liposomal formulations. For all the formulations, the mitoxantrone/HSPC molar ratio and the entrapment ratio were similar. The drug release experiment was first performed in phosphate-buffered saline using a dialysis method. Under these conditions, the release should be attributed to "dilution effect". As shown in Figure 2, both LHRH-MTX-SL and MTX-SL exhibited almost no release during the overall experimental period. The results clearly showed that dilution has little influence on the release of mitoxantrone from the liposomes.
The plasma-containing release buffer was also used to investigate the effect of plasma protein on mitoxantrone retention by liposomes. Because mitoxantrone has a strong affinity to some plasma proteins, protein binding might drive release of mitoxantrone from the vesicles. As shown in Figure 2, increased drug release of the two formulations was observed. After about 72 hours of incubation, more than $8 \%$ mitoxantrone was released from both LHRH-MTX-SL and MTX-SL. Overall, the release experiments in different release media clearly showed the modification of liposomes with gonadorelin had no influence on the mitoxantrone retention.

\section{Intracellular uptake of mitoxantrone formulations}

To confirm LHRH receptor-mediated internalization of the gonadorelin-modified liposomes, the extent of cellular uptake of different liposomal formulations was evaluated by confocal laser scanning fluorescence microscopy in LHRH receptor overexpressing or low-expressing cell lines. The cells were incubated with either the MTX-SL or LHRHMTX-SL ( $10 \mu \mathrm{g} / \mathrm{mL}$ as mitoxantrone) at $37^{\circ} \mathrm{C}$ for four hours. Cells treated with drug-free medium were used as controls. In LHRH receptor overexpressing MCF-7 cells (Figures $3 \mathrm{~A}$, 3B, and 3C), incubation with LHRH-MTX-SL (Figure 3B) resulted in more extensive internalization and cytoplasmic accumulation than MTX-SL (Figure $3 \mathrm{~A}$ ). In contrast, LHRHMTX-SL (Figure 3E) did not show improved uptake over MTX-SL (Figure 3D) in the LHRH low-expressing SK-OV-3 cell type (Figures 3D, 3E, and 3F).
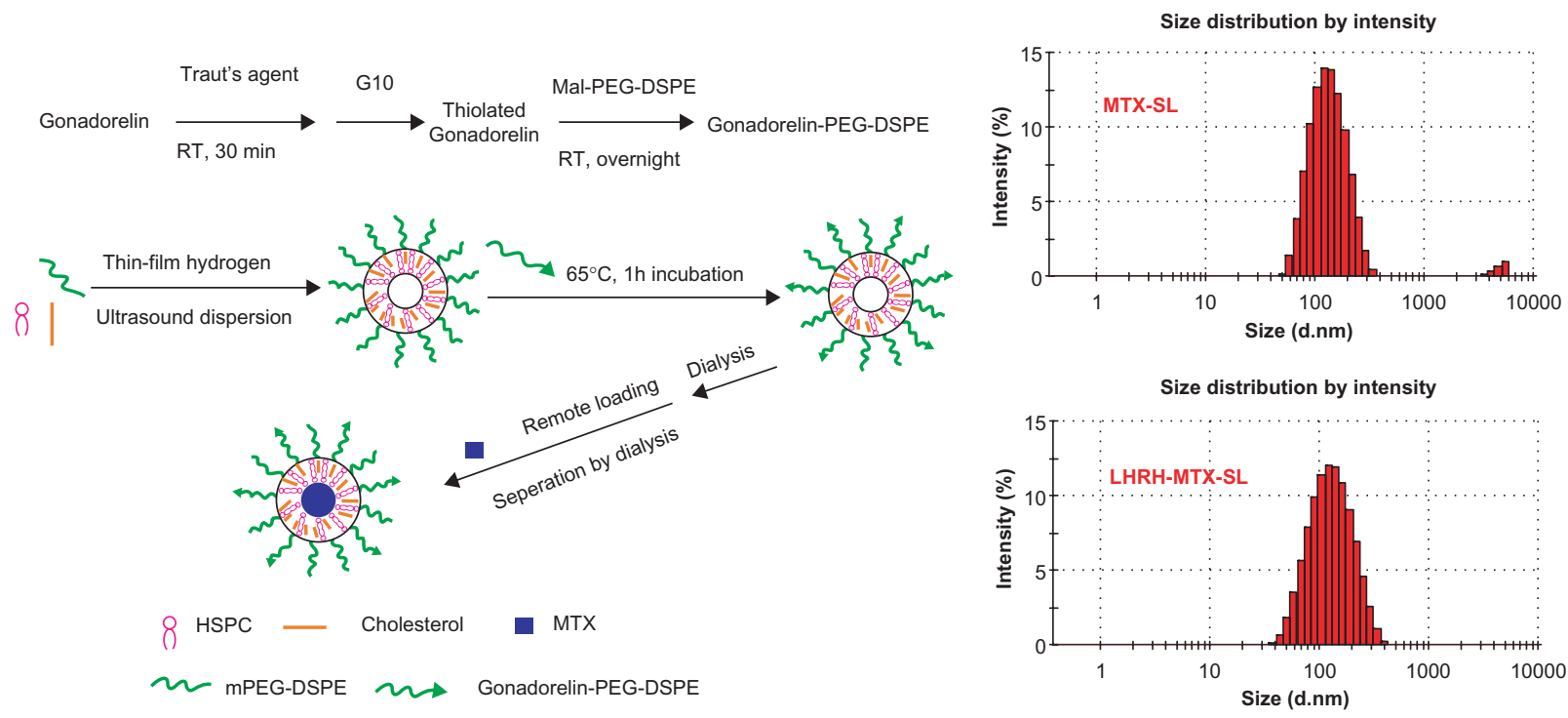

Figure I Synthesis of LHRH-PEG-DSPE and preparation of LHRH-MTX-SL.

Abbreviations: LHRH, luteinizing hormone-releasing hormone; PEG, polyethylene glycol; MTX, mitoxanthrone; SL, loaded liposomes. 
Table I Particle size, polydispersity index, zeta potential and gonadorelin:lipid ratio of liposomal formulations with or without mitoxantrone. The dynamic light scattering analysis was performed at $25^{\circ} \mathrm{C}$ and at a scattering angle of $90^{\circ}$. The obtained particle suspension was diluted appropriately in phosphate-buffered saline before measurement

\begin{tabular}{llllll}
\hline Formulations & MTX & Particlesize $(\mathbf{n m})$ & PDI & Zeta potential $(\mathbf{m V})$ & $\begin{array}{l}\text { Gonadorelin: lipid ratio } \\
(\mu \mathrm{g} / \mu \mathrm{mol})\end{array}$ \\
\hline Nontargeted & With & $124.7 \pm 0.97$ & $0.199 \pm 0.012$ & $-24.8 \pm 0.62$ & - \\
liposome & Without & $120.7 \pm 0.95$ & $0.157 \pm 0.002$ & $-25.3 \pm 1.44$ & - \\
Targeted & With & $146.1 \pm 0.94$ & $0.280 \pm 0.022$ & $-14.4 \pm 0.85$ & $4.63 \pm 0.09$ \\
liposome & Without & $133.0 \pm 1.12$ & $0.243 \pm 0.007$ & $-18.2 \pm 0.29$ & $4.80 \pm 0.12$ \\
\hline
\end{tabular}

Abbreviations: MTX, mitoxanthrone; PDI, polydispersity index.

\section{In vitro antitumor effect}

Comparison of the in vitro cytotoxicity of free mitoxantrone and mitoxantrone-loaded liposomal formulations was performed using MCF-7 cells, which are known to overexpress the LHRH receptor. Cells were incubated with either free mitoxantrone or its liposomal formulations ranging from $3 \times 10^{-1}$ to $3 \times 10^{2} \mathrm{ng} / \mathrm{mL}$ for $24-120$ hours. As shown in Figure 4, the empty liposomes exerted no effect on cell growth. Increasing the exposure time or drug concentration of either mitoxantrone or the mitoxantrone-loaded liposomal formulation led to improved efficacy, with the effects being
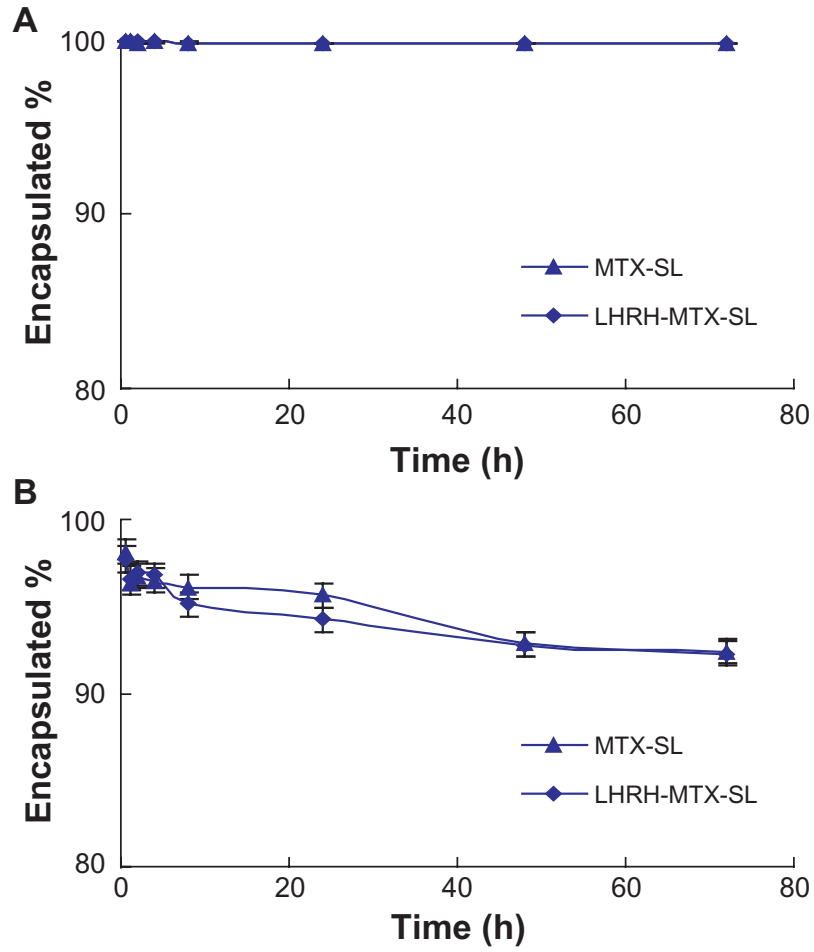

Figure 2 Release profiles of mitoxantrone from MTX-SL and LHRH-MTX-SL in phosphate-buffered saline A or isotonic glucose containing 10\% human plasma B Release of mitoxantrone from different liposome preparations was evaluated by a dialysis method, followed by high-performance liquid chromatography analysis for determination of mitoxantrone. Results are expressed as means \pm standard error of measurement of three independent measurements.

Abbreviations: LHRH, luteinizing hormone-releasing hormone; MTX, mitoxanthrone; SL, loaded liposomes. more significant with the gonadorelin-modified liposome compared with the control nontargeted liposome.

The average in vitro $\mathrm{IC}_{50}$ values for free mitoxantrone, MTX-SL, and MTX-LHRH-SL from three parallel cytotoxicity assays were $0.0445,11.7$, and $0.578 \mu \mathrm{g} / \mathrm{mL}$, respectively (Table 2). Free mitoxantrone was significantly more cytotoxic than either MTX-SL or MTX-LHRH-SL after 120 hours of incubation $(P<0.05)$. Targeted formulations were significantly more cytotoxic than nontargeted formulations $(P<0.05)$.

\section{Discussion}

In this study, we developed a simple yet highly efficient way to attach gonadorelin to liposomal membranes without compromising its specific activity or significantly affecting the amount or stability of the encapsulated drug. The LHRH ana$\log$, gonadorelin, was coupled to end-functionalized groups in PEG-DSPE micelles, and then the gonadorelin-PEG-DSPE conjugates were transferred in a simple incubation step
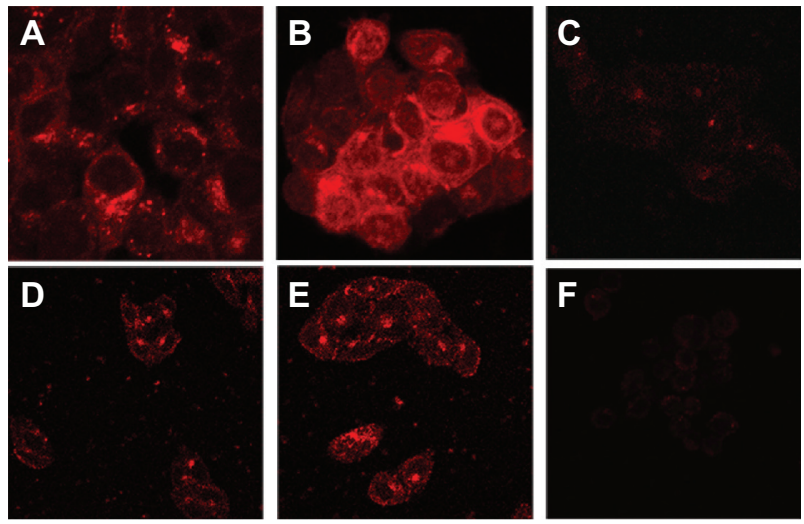

Figure 3 Uptake of different liposomes encapsulating mitoxantrone in various cell lines by confocal laser scanning fluorescence microscopy. Various cell lines were treated with either LHRH-MTX-SL or MTX-SL for four hours at $37^{\circ} \mathrm{C}$. A LHRH-MTX-SL in LHRH receptor high-expressing MCF-7 cells; B MTX-SL in LHRH receptor high-expressing MCF-7 cells; C MCF-7 cells treated with drug-free medium used as a control; D LHRH-MTX-SL in LHRH receptor low-expressing SK-OV-3 cells; E MTX-SL in LHRH receptor low-expressing SK-OV-3 cells; F SKOV-3 cells treated with drug-free medium used as a control.

Abbreviations: LHRH, luteinizing hormone-releasing hormone; MTX, mitoxanthrone; SL, loaded liposomes. 
Table 2 Cytotoxicity data $\left(\mathrm{IC}_{50}\right)$ for free mitoxantrone and mitoxantrone liposomal formulations (with or without LHRH) determined with MCF-7 cells $(n=3)$. Data are represented as percentage of control. Each assay was done in triplicate (mean \pm standard error of measurement). The cells were exposed to serial concentrations of free mitoxantrone, MTXSL, and LHRH-MTX-SL at $37^{\circ} \mathrm{C}$ for 120 hours. The cytotoxicity was evaluated using the MTT method. MCF-7 cell viability (as a percentage of control cells) was calculated as follows: Viability (\%) $=A_{\text {treated }} / A_{\text {control }} \times 100 \% . \quad I C_{50}$ was defined as the concentration of drug where cell growth and/or viability was $50 \%$ of that observed in control (drug-free) cultures in the MTT assay

\begin{tabular}{ll}
\hline Formulations & $\mathrm{IC}_{50}(\mu \mathrm{g} / \mathrm{mL})$ \\
\hline Free MTX & $0.0445 \pm 0.0063$ \\
MTX-SL & $11.7 \pm 1.9$ \\
LHRH-MTX-SL & $0.578 \pm 0.014$ \\
\hline
\end{tabular}

Abbreviations: LHRH, luteinizing hormone-releasing hormone; MTX, mitoxanthrone; SL, loaded liposomes.

from the micelles into the outer monolayer of preformed liposomes. This method represents a combinatorial approach to the design of targeted liposomes that minimizes manufacturing complexities and allows a variety of ligands to be inserted into a variety of preformed liposomes containing a large range of drugs. ${ }^{32}$
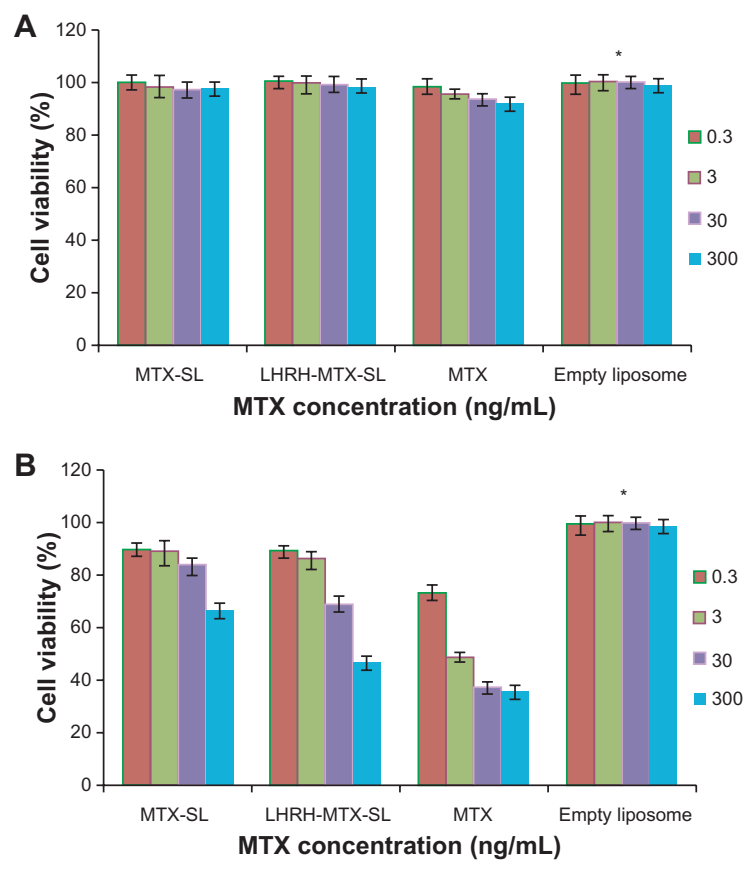

Figure 4 Viability of MCF-7 cells after treatment with mitoxantrone, mitoxantronecontaining liposomes, and empty liposomes for 24 hours A and I 20 hours B The cells were exposed to serial concentrations of free mitoxantrone, MTX-SL, LHRH-MTX$\mathrm{SL}$ at $37^{\circ} \mathrm{C}$ for 24 hours or 120 hours. The drug concentration of free mitoxantrone and MTX-SL used in this assay was $0.3,3.0,30,300 \mathrm{ng} / \mathrm{mL}$. Empty liposomes were used as a control. The antitumor effect was evaluated usings the MTT method. MCF-7 cell viability (as a percentage of control cells) was calculated as follows: Viability $(\%)=A_{\text {treated }} / A_{\text {control }} \times 100 \%$. Results are expressed as means \pm standard error of measurement from six independent measurements.
The covalent coupling of thiolated gonadorelin to the maleimide terminus of DSPE- PEG was specifically explored. This methodology was chosen because the reaction between thiol and maleimide groups has been reported to be one of the most efficient reactions in bioconjugate chemistry, resulting in a stable thioether linkage. ${ }^{33}$

Moreira et $\mathrm{al}^{29}$ observed that insertion of peptide ligands into PEGylated liposomes may cause some membrane perturbation, resulting in drug leakage from liposomes. Therefore, the loading of mitoxantrone was performed after insertion of the gonadorelin-PEG-DSPE conjugates. In these preparations, over $98 \%$ of drugs were entrapped within the liposomes. Subsequently, mitoxantrone release was evaluated in different media (Figure 2). After 72 hours at $37^{\circ} \mathrm{C}$, regardless of the incubation media, the drug release was approximately the same as that observed for control nontargeted liposomes, demonstrating that modification with gonadorelin had no influence on the membrane integrity of the liposomes.

Nonetheless, the liposomal formulations evaluated here exhibited sustained drug release characteristics. This finding is in agreement with a previous report that indicated liposomal mitoxantrone was difficult to release from vesicles. ${ }^{34}$ This behavior is consistent with the presence of drug precipitates in the liposomal interior. After ammonium sulfate gradient-mediated uptake, mitoxantrone forms insoluble precipitates within the liposome. The permeability characteristics of the drug in a precipitated form may be less dependent on membrane characteristics or the collapse of the transmembrane ammonium gradient. The efflux rate of drugs is proportional to the concentration of the soluble form of the drug, which will remain constant until the precipitated form is dissolved. Thus, the time required for drug release should be proportional to the amount of drug present in the precipitated form. ${ }^{35,36}$

In the cell uptake test, gonadorelin-modified liposomes showed significantly higher uptake by their respective target cells in vitro, as compared with the control nontargeted liposomes, implying that the gonadorelin-modified liposome binds specifically to the LHRH receptor and is efficiently internalized by LHRH receptor-mediated endocytosis. ${ }^{37}$ Endocytosis of the drug-liposome package into the cell interior would effectively limit the diffusion potential of the drug away from the target cell, which would in turn increase the amount of drug delivered to the target cell interior.

Using mitoxantrone-loaded, gonadorelin-modified liposomes, we showed that uptake by LHRH receptor overexpressing cells translates into increased cytotoxicity, as compared with the drug-loaded control without the 
gonadorelin-loaded liposome, probably due to distinct mechanisms of action. The cytotoxicity of MTX-SL is mainly owing to the gradual release of the encapsulated drug from liposomes close to the cell and uptake of the free drug into the target cell. The cytotoxicity of LHRH-MTX-SL may be attributed to receptor-mediated endocytosis of the liposomes, followed by slow breakdown of the liposomes in the cytoplasm and subsequent intracellular trafficking of the released drug. The empty gonadorelin-modified liposomes were nontoxic, indicating that cytotoxicity was not mediated by the LHRH peptide displayed on the liposome surface.

Cytotoxicity of the LHRH-MTX-SL formulation used in this study did not reach that of the free drug. This is in accordance with previous studies for anti-epidermal growth factor receptor immunoliposomal formulations of mitoxantrone. ${ }^{22}$ Several factors may account for this observed discrepancy. For example, subcellular localization of endocytosed immunoliposomes and the release rate of encapsulated drugs may all have profound influences on the efficiency of liposomal drugs. ${ }^{38}$ Endocytosed immunoliposomes are often routed through the endosomal and lysosomal pathways. ${ }^{39}$ For encapsulated mitoxantrone, release from liposomes and further escape from endosomes or lysosomes are required for translocation to the nucleus to effect disruption of DNA metabolism. In this study, the designed immunoliposomes exhibited sustained drug release characteristics. Moreover, the release rate of free drugs from the endosomes or lysosomes was also low, which depressed the action of mitoxantrone on tumor cells. Further development of $\mathrm{pH}$-sensitive liposome formulations may facilitate the collapse of liposomes, allowing more efficient release of encapsulated drug. ${ }^{40}$

\section{Conclusions}

The present study provides clear evidence that a simple immunomodification of mitoxantrone-loaded PEGylated liposomes with the LHRH analogs, Gonadorelin, against cancer-specific LHRH receptors results in successful development of a rather universal tumor-targeted mitoxantrone delivery system. LHRH-MTX-SL significantly facilitated specific delivery of mitoxantrone to LHRH receptor overexpressing tumor cells and efficiently inhibited tumor growth. This observation leads us to believe that LHRHMTX-SL has potential value for drug delivery therapy in future nanomedicine to treat human cancer and other diseases.

\section{Acknowledgments}

The authors are grateful to the Natural Science Foundation of China (No 50873114) and to the Central Level Nonprofit, Scientific Research Institutes' Basic R and D Operations Special Fund (Contract No 0609) for funding this work.

\section{Disclosure}

The authors report no conflicts of interest in this work.

\section{References}

1. Biganzoli L, Minisini A, Aapro M, Di Leo A. Chemotherapy for metastatic breast cancer. Curr Opin Obstet Gynecol. 2004;16(1):37-41.

2. Mezo G, Manea M. Receptor-mediated tumor targeting based on peptide hormones. Expert Opin Drug Deliv. 2010;7(1):79-96.

3. Allen TM, Cullis PR. Drug delivery systems: Entering the mainstream. Science. 2004;303(5665):1818-1822.

4. Drummond DC, Meyer O, Hong K, Kirpotin DB, Papahadjopoulos D. Optimizing liposomes for delivery of chemotherapeutic agents to solid tumors. Pharmacol Rev. 1999;51:691-743.

5. Elbayoumi TA, Torchilin VP. Tumor-specific anti-nucleosome antibody improves therapeutic efficacy of doxorubicin-loaded long-circulating liposomes against primary and metastatic tumor in mice. Mol Pharm. 2009;6(1):246-254.

6. Kakar SS, Jennes L. Expression of gonadotropin-releasing hormone and gonadotropin- releasing hormone receptor mRNAs in various non reproductive human tissues. Cancer Lett. 1995;98(1):57-62.

7. Schally AV, Szepeshazi K, Nagy A, Comaru-Schally AM, Halmos G. New approaches to therapy of cancers of the stomach, colon and pancreas based on peptide analogue. Cell Mol Life Sci. 2004;61(9): 1042-1068.

8. Schally AV, Comaru-Schally AM, Nagy A, et al. Hypothalamic hormones and cancer. Front Neuroendocrinol. 2001;22(4):248-291.

9. Nagy A, Schally AV. Targeting of cytotoxic luteinizing hormonereleasing hormone (LH-RH) analogs to breast, ovarian, endometrial and prostate cancers. Biol Reprod. 2005;73(5):851-859.

10. Dharap SS, Qiu B, Williams GC, Sinko P, Stein S, Minko T. Molecular targeting of drug delivery systems to ovarian cancer by BH3 and LHRH peptides. J Control Release. 2003;91(1-2):61-73.

11. Nagy A, Schally AV. Cytotoxic analogues of luteinizing hormonereleasing hormone (LH-RH): A new approach to targeted chemotherapy. Drugs Fut. 2002;27:359-370.

12. Westphalen S, Kotulla G, Kaiser F, et al. Receptor mediated antiproliferative effects of the cytotoxic LHRH agonist AN-152 in human ovarian and endometrial cancer cell lines. Int J Oncol. 2000;17(5):1063-1069.

13. Krebs LJ, Wang X, Pudavar HE, et al. Regulation of targeted chemotherapy with cytotoxic luteinizing hormone-releasing hormone analogue by epidermal growth factor. Cancer Res. 2000;60(15):4194-4199.

14. Kakar SS, Jin H, Hong B, Eaton JW, Kang KA. LHRH receptor targeted therapy for breast cancer. Adv Exp Med Biol. 2008;614:285-296.

15. Faulds D, Balfour JA, Chrisp P, Langtry HD. Mitoxantrone: A review of its pharmacodynamic and pharmacokinetic properties, and therapeutic potential in the chemotherapy of cancer. Drugs. 1991;41(3):400-449.

16. Dunn CJ, Goa KL. Mitoxantrone: A review of its pharmacological properties and use in acute nonlymphoblastic leukaemia. Drugs Aging. 1996;9(2):122-147.

17. Ugwu S, Zhang A, Parmar M, et al. Preparation, characterization, and stability of liposome-based formulations of mitoxantrone. Drug Dev Ind Pharm. 2005;31(2):223-229.

18. Li C, Cui J, LiY, et al. Copper ion-mediated liposomal encapsulation of mitoxantrone: The role of anions in drug loading, retention and release. Eur J Pharm Sci. 2008;34(4-5):333-344. 
19. Cui J, Li C, Wang L, et al. Ni2+-mediated mitoxantrone encapsulation: Improved efficacy of fast release formulation. Int J Pharm. 2009; 368(1-2):24-30.

20. Li C, Cui J, Wang C, et al. Lipid composition and grafted PEG affect in vivo activity of liposomal mitoxantrone. Int J Pharm. 2008; 362(1-2):60-66.

21. Kawano K, Onose E, Hattori Y, Maitani Y. Higher liposomal membrane fluidity enhances the in vitro antitumor activity of folate-targeted liposomal mitoxantrone. Mol Pharm. 2009;6(1):98-104.

22. Beuttler J, Rothdiener M, Müller D, Frejd FY, Kontermann RE. Targeting of epidermal growth factor receptor (EGFR)-expressing tumor cells with sterically stabilized affibody liposomes (SAL). Bioconjug Chem. 2009;20(6):1201-1208.

23. Dharap SS, Wang Y, Chandna P, et al. Tumor-specific targeting of an anticancer drug delivery system by LHRH peptide. Proc Natl Acad Sci US A. 2005;102(36):12962-12967.

24. Leuschner C, Kumar CS, Hansel W, Soboyejo W, Zhou J, Hormes J. LHRH-conjugated magnetic iron oxide nanoparticles for detection of breast cancer metastases. Breast Cancer Res Treat. 2006;99(2): 163-176.

25. Sundaram S, Durairaj C, Kadam R, Kompella UB. Luteinizing hormonereleasing hormone receptor-targeted deslorelin-docetaxel conjugate enhances efficacy of docetaxel in prostate cancer therapy. Mol Cancer Ther. 2009;8(6):1655-1665

26. Saad M, Garbuzenko OB, Ber E, et al. Receptor targeted polymers, dendrimers, liposomes: Which nanocarrier is the most efficient for tumor-specific treatment and imaging? J Control Release. 2008;130: 107-114.

27. Qin Y, Song QG, Zhang ZR, et al. Ovarian tumor targeting of docetaxelloaded liposomes mediated by luteinizing hormone-releasing hormone analogues. In vivo distribution in nude mice. Arzneimittelforschung. 2008;58(10):529-534.

28. Allen TM, Sapra P, Moase E. Use of the post-insertion method for the formation of ligand-coupled liposomes. Cell Mol Biol Lett. 2002;7(3): 889-894.

29. Moreira JN, Ishida T, Gaspar R, Allen TM. Use of the post-insertion technique to insert peptide ligands into pre-formed stealth liposomes with retention of binding activity and cytotoxicity. Pharm Res. 2002; 19(3):265-269.
30. Derycke AS, De Witte PA.Transferrin-mediated targeting of hypericin embedded in sterically stabilized PEG-liposomes. Int J Oncol. 2002; 20(1):181-187.

31. Johnson JL, Ahmad A, Khan S, et al. Improved liquid chromatographic method for mitoxantrone quantification in mouse plasma and tissues to study the pharmacokinetics of a liposome entrapped mitoxantrone formulation. J Chromatogr B Analyt Technol Biomed Life Sci. 2004; 799(1):149-155.

32. Elbayoumi TA, Torchilin VP. Tumor-targeted immunoliposomes for delivery of chemotherapeutics and diagnostics. J Pharm Innov. 2008; 3:51-58.

33. Allen TM, Brandeis E, Hansen CB, Kao GY, Zalipsky S. A new strategy for attachment of antibodies to sterically stabilized liposomes resulting in efficient targeting to cancer cells. Biochim Biophys Acta. 1995;1237(2):99-108

34. Regev R, Yeheskely-Hayon D, Katzir H, Eytan GD. Transport of anthracyclines and mitoxantrone across membranes by a flip-flop mechanism. Biochem Pharmacol. 2005;70(1):161-169.

35. Li C, Cui J, Wang C, et al. Encapsulation of mitoxantrone into pegylated SUVs enhances its antineoplastic efficacy. Eur J Pharm Biopharm 2008;70(2):657-665.

36. Yamauchi M, Tsutsumi K, Abe M, Uosaki Y, Nakakura M, Aoki N. Release of drugs from liposomes varies with particle size. Biol Pharm Bull. 2007;30(5):963-966.

37. Nagy A, Schally AV, Armatis P, et al. Cytotoxic analogues of luteinizing hormone-releasing hormone containing doxorubicin or 2-pyrrolinodoxorubicin, a derivative 500-1000 times more potent. Proc Natl Acad Sci U S A. 1996;93(14):7269-7273.

38. Roth A, Drummond DC, Conrad F, et al. Anti-CD166 single chain antibody-mediated intracellular delivery of liposomal drugs to prostate cancer cells. Mol Cancer Ther. 2007;6(10):2737-2746.

39. Collins D, Maxfield F, Huang L. Immunoliposomes with different acid sensitivities as probes for the cellular endocytic pathway. Biochim Biophys Acta. 1989;987(1):47-55.

40. Kim MJ, Lee HJ, Lee IA, et al. Preparation of pH-sensitive, longcirculating and EGFR-targeted immunoliposomes. Arch Pharm Res. 2008;31(4):539-546.
International Journal of Nanomedicine

\section{Publish your work in this journal}

The International Journal of Nanomedicine is an international, peerreviewed journal focusing on the application of nanotechnology in diagnostics, therapeutics, and drug delivery systems throughou the biomedical field. This journal is indexed on PubMed Central, MedLine, CAS, SciSearch $₫$, Current Contents $₫ /$ Clinical Medicine,

\section{Dovepress}

Journal Citation Reports/Science Edition, EMBase, Scopus and the Elsevier Bibliographic databases. The manuscript management system is completely online and includes a very quick and fair peer-review system, which is all easy to use. Visit http://www.dovepress.com/ testimonials.php to read real quotes from published authors. 